Original Article

\title{
FORMULATION AND EVALUATION OF CILNIDIPINE MUCOADHESIVE BUCCAL FILM BY SOLVENT CASTING TECHNIQUE FOR THE TREATMENT OF HYPERTENSION
}

\author{
SHIFA SHAUKAT HAJU ${ }^{*}$, SHEELA YADAV ${ }^{1}$ \\ 1Department of Pharmaceutics, H. K. College of Pharmacy, Relief Road, Pratiksha Nagar, Oshiwara, Jogeshwari West, Mumbai 400102, India \\ Email: shifahaju123@gmail.com
}

Received: 05 Jul 2021, Revised and Accepted: 02 Aug 2021

\begin{abstract}
Objective: Buccal drug delivery is the most suited route for local as well as systemic delivery of drugs. Cilnidipine is an L/N type dihydropyridine $4^{\text {th }}$ generation calcium channel blocker (CCB), which decreases hypertension by blocking the N-type calcium channel to attenuate vascular sympathetic neurotransmission. It has high first-pass metabolism leading to low bioavailability. Hence the present research work was undertaken to formulate mucoadhesive buccal film of Cilnidipine with an objective to enhance therapeutic efficacy, bioavailability and was developed to administer into the unconscious and less-co-operative patients.
\end{abstract}

Methods: Cilnidipine buccal films were prepared by a solvent-casting technique using various concentrations of mucoadhesive-polymers such as Hydroxyl propyl methylcellulose (HPMC) E15 and K4M and ethyl-cellulose as backing-layer, which acts like a patch providing unidirectional drug release. Prepared films were evaluated for their weight variation, thickness, surface-pH, swelling-index, drug content uniformity, in vitro residence time, folding endurance, tensile strength, in vitro release and permeability studies.

Results: The infra-red (IR) spectra showed no interaction, and Physico-chemical characteristics were found within the limit. Swelling of the film increases with increasing concentration of polymers and \%drug content of all formulations found to be in the range of $92.13 \% \pm 0.94 \%$ to $97.92 \% \pm 0.35 \%$. The formulation $\mathrm{F} 5$, showed a promising tensile strength, folding endurance and in vitro drug release of about $95.18 \pm 0.03 \%$, thus can be selected as an optimized formulation of mucoadhesive buccal film.

Conclusion: The formulation of Cilnidipine mucoadhesive buccal film was found to be satisfactory and reasonable.

Keywords: Buccal film, Cilnidipine, Solvent-casting, HPMC, Mucoadhesive

(C) 2021 The Authors. Published by Innovare Academic Sciences Pvt Ltd. This is an open-access article under the CC BY license (https://creativecommons.org/licenses/by/4.0/)

DOI: https://dx.doi.org/10.22159/ijpps.2021v13i9.42641. Journal homepage: https://innovareacademics.in/journals/index.php/ijpps.

\section{INTRODUCTION}

Among the various routes of drug delivery, oral route is the most convenient, easily preferred and patient compliance one. However, drugs administrated orally undergoes hepatic first-pass metabolism and enzymatic degradation in the gastrointestinal tract (GI) or both. These are the main reason the oral route is prohibited for the certain class of drugs. Transmucosal delivery of drug through various mucosal surfaces (nasal, rectal, vaginal, ocular and oral mucosa: buccal, sublingual) may be a possible alternative solution over oral drug delivery system [1]. In recent year, potential interest has been shown in the development of patient compliance formulation for better and sustained drug delivery is an integral part of research [2]. Among the various trans-mucosal routes, buccal mucosa has unique physiological features as an ideal route for mucoadhesive drug delivery [3]. Its anatomical and physiological features, like the presence of smooth muscles with high vascular perfusion, have direct access to the systemic circulation through the internal jugular vein, which bypasses the drug from hepatic first-pass metabolism and hence can potentially improve the bioavailability [4]. It is the most suited route for local as well as systemic drug administration. Buccal films have gained importance as efficacious, economic, patient-friendly and novel drug delivery systems [5].

The drug release and permeation through the buccal mucosa layer are affected by the microenvironment of the mucosa. The microenvironment of the mucosa may be altered or changed with the support of a well-designed mucoadhesive drug delivery system. This system designed and developed with the support of mucoadhesive polymer which is generally of high molecular weight and of high viscosity grades with higher flexibility and optimum chain length [6]. The main property of the buccal film, among the various mucoadhesive drug delivery, is that due to the large surface area of film, it allows quick hydration of film, which accelerated drug absorption as compared to buccal tablet and buccal or oral gels, in terms of comfort and flexibility [7]. The order of permeability of drug molecule through oral cavity is given as sublingual $>$ buccal $>$ gingival $>$ palatal [8] .

Cilnidipine is an $\mathrm{L} / \mathrm{N}$ type dihydropyridine $4^{\text {th }}$ generation calcium channel blocker (CCB), used mainly in the treatment of uncontrolled blood pressure and post-stroke hypertensive patients. It is a BCS class II drug having low bioavailability of $06-30 \%$ due to hepatic first-pass metabolism [9]. Hence to improve the therapeutic efficacy and bioavailability the drug may be administrated by the buccal route through mucoadhesive buccal films. Buccal delivery of Cilnidipine may bypass hepatic first-pass metabolism and improve bioavailability. Hence the present work deals with the formulation and characterization of mucoadhesive buccal film using mucoadhesive polymer hydroxyl propyl methylcellulose (HPMC) E15, K4M and ethyl cellulose as a backing layer.

\section{MATERIALS AND METHODS}

Cilnidipine was a gift sample from Pure Chem Pvt. Ltd. Ankleshwar, Gujarat. HPMC E5, HPMCE15, HPMC K4M and Ethylcellulose were gift samples from Colorcon Pvt. Ltd. Verna, Goa. All other chemicals and reagents were analytical and pharmacopeial grade.

\section{Preformulation studies}

Preliminary trials for selecting suitable polymers and plasticizer

Preliminary trials of formulation development were carried out using film-forming polymers such as HPMC E3, E5, E15 and K4M etc. HPMC E3 shows thin film formation and E5 films were easily prone to breaking and cracking. E15 has good film-forming property, good folding endurance and a satisfied appearance. HPMC controlled released polymer grade, HPMC K4M show good results in buccal film formulation. Propylene glycol was taken $10 \% \mathrm{w} / \mathrm{w}$ of the polymeric 
concentration, whereas if the concentration of plasticizer was altered it leads to poor flexibility at lower concentration and sticky appearance at higher concentration.

\section{Determination of melting point of the drug}

Melting point of Cilnidipine was determined by using the capillary tube method using melting point apparatus.

\section{Fourier transform infrared spectroscopy (FTIR) studies}

Compatibility of Cilnidipine with excipients was confirmed by FTIR studies. FTIR study was conducted using the potassium bromide disc (pellet) method. The FTIR spectrum of pure drug Cilnidipine and a physical mixture of Cilnidipine with film-forming polymer (HPMC E15, HPMC K4M), plasticizer (Propylene glycol) and backing layer excipients were recorded using FTIR (IR Affinity S1, Shimadzu, Kyoto, Japan).

\section{Differential scanning calorimetry (DSC) studies}

The DSC thermogram of pure drug was recorded using Differential Scanning Calorimetry equipped with a computerized data station. Sample was weighed and heated in a closed pierced aluminum pan at a heating rate of $10{ }^{\circ} \mathrm{C} / \mathrm{min}$ between $30{ }^{\circ} \mathrm{C}$ and $300{ }^{\circ} \mathrm{C}$ and nitrogen flow rate $25 \mathrm{ml} / \mathrm{min}$. It provides an idea about the interaction of various materials at different temperatures. It also allows studying the possible degradation pathways of the materials. It gives an idea about the physical and chemical interaction between the drugs.

\section{Determination of absorption maximum ( $\lambda$ max) of the drug}

Stock solution of the drug was prepared using phosphate buffer solution (PBS) of pH 6.8 to give a concentration of $100 \mathrm{ppm} .1 \mathrm{ml}$ from above solution was diluted up to $10 \mathrm{ml}$ in a volumetric flask to give concentration of $10 \mathrm{ppm}$. Wavelength was scan from 400-200 $\mathrm{nm}$ was done to find the absorbance maxima.

\section{Method}

\section{Solvent casting technique}

The mucoadhesive buccal film is prepared by solvent casting technique; it is one of the simple methods than the other buccal film formulation methods and is the most widely accepted manufacturing process utilized for the production of films. Solvent casting technique has greater clarity and uniformity of thickness than extrusion method. In this method, the required quantity of polymer dissolved in distilled water. On the other hand, active pharmaceutical ingredients (API) and other excipients are dissolved in a suitable solvent system. Afterwards both the solutions are mixed and stirrer to form homogeneous mixture. This resultant solution is called as "casting solution". The casting solution is poured into casting mould and the solvent is evaporated. The method for preparation of Cilnidipine of mucoadhesive buccal film and backing layer given below as follows: [10]

\section{Preparation of mucoadhesive buccal film}

Mucoadhesive buccal film of Cilnidipine was prepared by a solventcasting technique using a film-forming mucoadhesive polymer as per the formula given in table 1. Initially, the polymers HPMC E15, HPMC K4M were weighed accurately and dissolved in $2 \mathrm{ml}$ ethanol and $3 \mathrm{ml}$ distilled water. The beaker containing polymers, ethanol and water was kept aside for $15 \mathrm{~min}$ for swelling of polymers. Then the polymeric solution stirred for $1 \mathrm{~h}$ on the magnetic stirrer to get the clear and bubbles-free solution. Plasticizer $10 \% \mathrm{w} / \mathrm{w}$ of polymeric concentration was added to the polymeric solution with continuous stirring. In another beaker Cilnidipine with sodium saccharin were dissolved in a sufficient quantity of solvent (Ethanol: water 1:1). The solution was continuously stirred for $4 \mathrm{~h}$. Then the drug-containing solution and polymeric solution with other excipients mixed evenly with the help of a magnetic stirrer to form the homogeneous casting solution. The whole solution poured into the pre-lubricated glass petri-plate at $40{ }^{\circ} \mathrm{C}$ and left for $12 \mathrm{~h}$. The film was removed carefully after drying and cut into $2 \times 2 \mathrm{~cm}^{2}$. The film was stored in butter paper covered with aluminum foil and stored at room temperature.

\section{Preparation of backing layer}

For the preparation of the formulations, a glass petri-plate of $9 \mathrm{~cm}$ diameter was utilized as a film casting surface. The accurately weighed 5\% Ethylcellulose (20 cps) was dissolved in the solvent mixture isopropyl alcohol: acetone (3:1) and kept for stirring for 4-5 h. 1\% Amaranth solution was used to give color to the backing layer. The backing solution was poured slowly to the pre-lubricated glass petri-plate and air-dried overnight. The backing layer formed after drying was removed carefully and cut in to $3 \times 3 \mathrm{~cm}^{2}$ and stored at room temperature covered in butter paper wrapped.

Table 1: Composition of mucoadhesive buccal film

\begin{tabular}{|c|c|c|c|c|c|c|c|c|c|}
\hline \multirow[t]{2}{*}{ Formulation ingredients } & \multicolumn{9}{|c|}{ Formulation code } \\
\hline & F1 & F2 & F3 & F4 & F5 & F6 & F7 & F8 & F9 \\
\hline Cilnidipine (mg) & 158.96 & 158.96 & 158.96 & 158.96 & 158.96 & 158.96 & 158.96 & 158.96 & 158.96 \\
\hline HPMC E15 \% & 3 & 3 & 3 & 4 & 4 & 4 & 5 & 5 & 5 \\
\hline НРМС К4М \% & 0.5 & 1.5 & 2.5 & 0.5 & 1.5 & 2.5 & 0.5 & 1.5 & 2.5 \\
\hline Propylene Glycol \% & 10 & 10 & 10 & 10 & 10 & 10 & 10 & 10 & 10 \\
\hline Sodium saccharin \% & 0.1 & 0.1 & 0.1 & 0.1 & 0.1 & 0.1 & 0.1 & 0.1 & 0.1 \\
\hline Ethanol/Distilled water $(\mathrm{ml})$ & q. $s$ & q. $s$ & q. $s$ & q. $s$ & q. $s$ & q. $s$ & q. $s$ & q. $s$ & q. $s$ \\
\hline
\end{tabular}

\section{The amount of drug per batch dose calculation}

Dose of drug per film $=10 \mathrm{mg}$

An area of one film $=4 \mathrm{~cm}^{2}$

Area of petri plate $=63.585 \mathrm{~cm}^{2}$

Drug to be added per batch

$=($ Dose of drug per film $\times$ Area of petri plate $)$

$\div$ Area of 1 film.

$=(10 \times 63.585) \div 4=158.96 \mathrm{mg}$.

\section{Evaluation of cilnidipine mucoadhesive buccal film}

\section{Appearance}

Visual inspection of mucoadhesive buccal films was assessed for their appearance of visible imperfections and surface texture of films were analyzed by feel or contact [11].

\section{Weight variation}

Three films of every 9 films of $2 \times 2 \mathrm{~cm}^{2}$ for each formulation were weighed individually and calculated. A calibrated electronic weighing balance is used for weighing mucoadhesive buccal film. The mean weight of all films is calculated [12].

\section{Thickness}

A calibrated digital micrometer screw gauge is used to determine the thickness of the mucoadhesive buccal film. The thickness of films was measured at five different points (four on the corners and one in the center) using a digital micrometer screw gauge. The average thickness of all films is calculated [13].

\section{Folding endurance}

Folding endurance of the films was determined by repeatedly folding the small strip of size $\left(2 \times 2 \mathrm{~cm}^{2}\right)$ at the same place till it breaks. The number of times the film can be folded at the similar place without 
breaking give the value of folding endurance. The three readings average and standard deviation of all films is calculated [14].

\section{Tensile strength}

Mucoadhesive buccal film of size $2 \times 2 \mathrm{~cm}^{2}$ was placed between the clamp of the stand and clip through which the weighing pan was attached above the ground level in the air. For the measurement of tensile strength of the film the weights were added to the pan till the film breaks. The load causing the deformation and rupture of film was calculated by the following equation: [14]

$$
\begin{aligned}
& \text { Tensile strenght } \\
& =\text { weight placed on pan along with clip and pan }(\mathrm{kg}) \\
& / \text { width of film }(\mathrm{cm}) \times \text { thickness of film }(\mathrm{cm})
\end{aligned}
$$

Unit $\mathrm{Kg} / \mathrm{cm}^{2}$

Multiply Kg/ $\mathrm{cm}^{2}$ by 0.098 (acceleration due to gravity) to get $\mathrm{N} / \mathrm{mm}^{2}$.

\section{Mucoadhesive strength}

The mucoadhesive strength is determined by an analytical balance. Mucoadhesive buccal film is placed on the glass slide by placing a drop of water on slide on the one side of analytical balance another end weighing pan was attached. Weight was slowly added to the pan until glass slide get detached from film. Weight required to detach the film from the glass slide is measured as mucoadhesive strength. The mucoadhesive strength of each formulation $(\mathrm{n}=3)$ was calculated [14].

\section{Surface pH}

For determining the surface $\mathrm{pH}$ of mucoadhesive buccal film, three buccal films of each formulation were allowed to swell for $15 \mathrm{~min}$ at room temperature in the contact of $1 \mathrm{ml}$ distilled water (pH 6.6 \pm 0.5$)$, and the $\mathrm{pH}$ was determined by bringing the electrode in contact of buccal film surface and allowing equilibrate for $1 \mathrm{~min}$ [15]. The surface $\mathrm{pH}$ was recorded using $\mathrm{pH}$ meter (Toshcon industries Pvt. Ltd.).

\section{Drug content uniformity}

Film of dimension $2 \times 2 \mathrm{~cm}^{2}$ was added in $100 \mathrm{ml}$ of phosphate buffer $\mathrm{pH}$ 6.8 , stirred continuously in benchtop orbital shaker for $24 \mathrm{~h}$. Additionally, this solution was filtered, suitably dilution, and analyzed at $240 \mathrm{~nm}$ using a UV spectrophotometer. The average and standard deviation of drug content for three films was taken as final reading [16].

\section{Swelling index}

Swelling index was determined by positioning the buccal film of size $2 \times 2 \mathrm{~cm}^{2}$ pre-weighed on wire mesh placed into a clean petri plate filled with $15 \mathrm{ml}$ of phosphate buffer $\mathrm{pH}$ 6.8. Buccal film weight was measured at the regular interval till it remained constant and an average of 3 films was taken. Swelling index (SI) was calculated by using the following formula [17].

$$
\text { Swelling index }(\mathrm{SI})=(\mathrm{W}-\mathrm{Wo}) / \mathrm{WO}
$$

Where;

$$
\begin{aligned}
& \text { SI = Swelling index } \\
& \text { W = Final weight of buccal film } \\
& \text { Wo = Initial weight of buccal film. }
\end{aligned}
$$

\section{Percentage moisture uptake}

In order to evaluate the films of dimension $2 \times 2 \mathrm{~cm}^{2}$ were weighed and accurately placed in the desiccator at room temperature for 3 days with saturated ammonium chloride solution and maintained 79.5\% Relative Humidity. The films were taken out and weighed after 3days. Percentage of moisture uptake was calculated using the following formula [18].

Percentage moisture uptake $=\left[\frac{\text { Final weight }- \text { Initial weight }}{\text { Final weight }}\right] \times 100$

\section{Percentage moisture loss test}

In an evaluation of percent moisture loss, the accurately weighed film was placed in the desiccator containing calcium chloride (fused anhydrous) for $3 \mathrm{~d}$. After $3 \mathrm{~d}$ the film was reweighed, percentage moisture loss was calculated by the following formula [18].

$$
\text { Percentage moisture loss }=\left[\frac{\text { Initial weight }- \text { Final weight }}{\text { Initial weight }}\right] \times 100
$$

\section{Residence time}

Residence time of film was obtained on goat mucosal surface. A film of dimension $2 \times 2 \mathrm{~cm}^{2}$ was placed on outer layer of mucosa, and both the layer were put into the petri plate filled with $5 \mathrm{ml}$ of PBS pH 6.8 . After that the petri plate was placed in benchtop orbital shaker at 50 rpm at $37{ }^{\circ} \mathrm{C}$. Residence time is determined by the time at which buccal film disintegrates on buccal mucosa [19].

\section{In vitro drug release}

For in vitro drug release study USP type I apparatus (Basket type) dissolution test apparatus containing $250 \mathrm{ml}$ of PBS of pH 6.8 as a dissolution medium at $37 \pm 0.5^{\circ} \mathrm{C}$ temperature and speed at $50 \mathrm{rpm} .5$ $\mathrm{ml}$ of sample solution was withdrawn at time intervals of $15 \mathrm{~min}, 30$ min, $45 \mathrm{~min}, 1 \mathrm{~h}, 2 \mathrm{~h}, 4 \mathrm{~h}, 6 \mathrm{~h}, 8 \mathrm{~h}, 12 \mathrm{~h}$, and $24 \mathrm{~h}$ and equilibrated with a new or fresh dissolution medium to maintain sink state. Drug release was analyzed spectrophotometrically at a $\lambda \max$ of $240 \mathrm{~nm}$ using UV-visible spectroscopy (Shimadzu, UV-1800) [20].

\section{In vitro diffusion studies}

An in vitro diffusion study was performed by using Franz diffusion cell assembly. It consists of two compartments, one of the receptor chambers containing a PBS of pH 6.8 and another donor compartment containing mucoadhesive buccal film (patch) of $10 \mathrm{mg}$ of the drug. A dialysis membrane (molecular size 12000-14000 was previously soaked for 24 h. Dialysis membrane was placed in contact of PBS filled in receptor compartment to avoid disruption in the ongoing process; it was ensured that no air bubbles were seen between the dialysis membrane and liquid surface of PBS. The temperature was maintained at $37 \pm 0.5^{\circ}$ Cat $50 \mathrm{rpm}$ using a magnetic stirrer. $0.5 \mathrm{ml}$ of the sample was withdrawn from the receptor chamber side tube at the time interval of $15 \mathrm{~min}, 30 \mathrm{~min}, 45$ min, $1 \mathrm{~h}, 2 \mathrm{~h}, 4 \mathrm{~h}, 6 \mathrm{~h}, 8 \mathrm{~h}, 12 \mathrm{~h}$, and $24 \mathrm{~h}$ and equilibrated with a new or fresh dissolution medium to maintain sink state. Suitable dilution was carried out and was spectroscopically analyzed at a $\lambda \max$ of $240 \mathrm{~nm}$ using UVvisible spectroscopy (Shimadzu, UV-1800) [20].

\section{Ex vivo permeation studies}

The ex-vivo permeation studies were carried out using a modified Franz diffusion cell. The mucoadhesive buccal film of Cilnidipine through an excised layer of goat buccal mucosa (washed in isotonic phosphate buffer (pH 6.6) after excised and trimming from the sides) was obtained from local slaughterhouse. The receptor compartment of Franz diffusion cell containing phosphate buffer of $\mathrm{pH} 7.4(20 \mathrm{ml})$ medium and mini magnetic bead was placed in receptor compartment. A mucoadhesive buccal film of the dimension of $2 \times 2 \mathrm{~cm}^{2}$ optimized batch was placed over the goat buccal mucosal membrane fitted between the donor and receptor compartment. The whole assembly was placed on a magnetic stirrer; the temperature was maintained at $37 \pm 0.5^{\circ} \mathrm{C}$ at $50 \mathrm{rpm} .0 .5 \mathrm{ml}$ of the sample was withdrawn from the receptor compartment side chain and replace with fresh medium at a regular time interval of $15 \mathrm{~min}, 30$ min, $45 \mathrm{~min}, 1 \mathrm{~h}, 2 \mathrm{~h}, 4 \mathrm{~h}, 6 \mathrm{~h}, 8 \mathrm{~h}, 12 \mathrm{~h}$, and $24 \mathrm{~h}$. Suitable dilution was carried out and was spectroscopically analyzed at a $\lambda$ max of $240 \mathrm{~nm}$ using UV-visible spectroscopy (Shimadzu, UV-1800) to determine the amount of drug permeated [21].

\section{Stability studies}

A stability study of optimized formulation was executed as per ICH guidelines. The single film of dimension $2 \times 2 \mathrm{~cm}^{2}$ was wrapped individually in butter paper followed by packing in aluminum foil and maintained at room temperature $25 \pm 2{ }^{\circ} \mathrm{C}$ and $60 \pm 5 \% \mathrm{RH}$ and placed in accelerated stability condition at $40 \pm 2{ }^{\circ} \mathrm{C}$ and $75 \pm 5 \% \mathrm{RH}$ for the period of 3 months. Changes in appearance, folding endurance, tensile strength, drug content, \% drug release of the stored mucoadhesive buccal film (patch) were analyzed at a regular interval for 3 months [22].

\section{RESULTS AND DISCUSSION}

\section{Determination of melting point of the drug}

Melting point of Cilnidipine was found to be in the range of 108-110 ${ }^{\circ} \mathrm{C}$ and it complies with the IP standard, thus indicating the purity of the sample. 


\section{Drug excipient compatibility studies by FTIR}

IR spectrum of Cilnidipine (drug), physical mixture with excipients and backing layer also was recorded and it was found in accordance with the reported peaks. There are no observed significant peak shifts and no generation of a new peak, although there might be no possible interaction between drug and excipients of buccal film FTIR spectra were found to be pure, stable and unaltered [23].

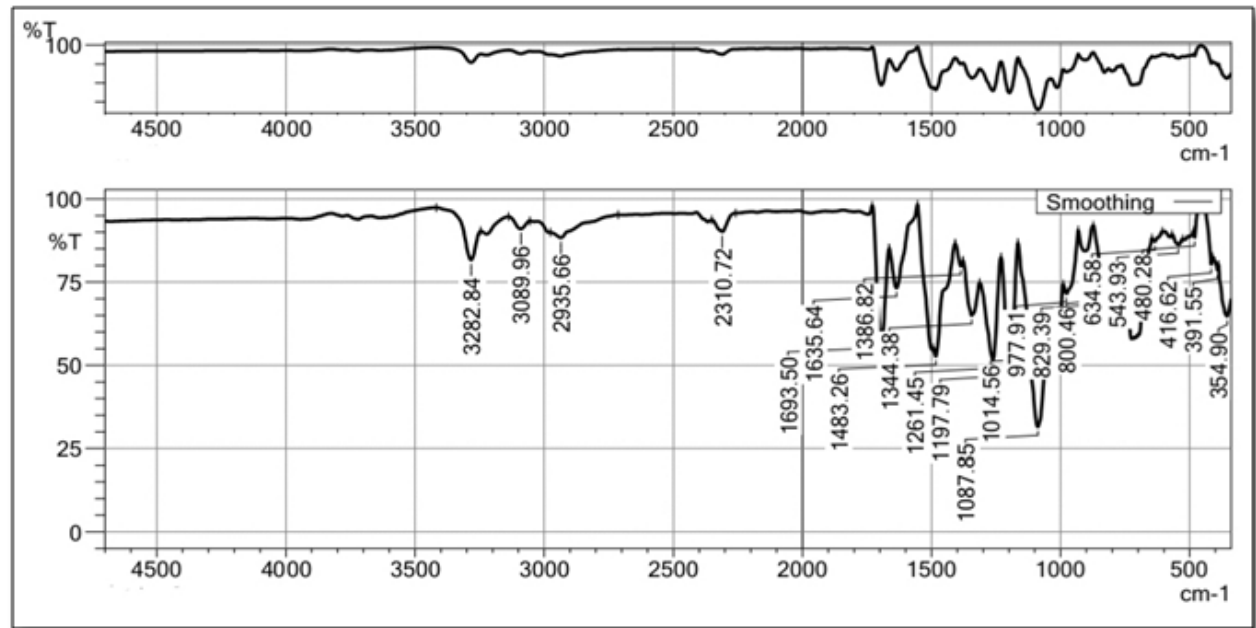

Fig. 1: IR spectrum of pure cilnidipine

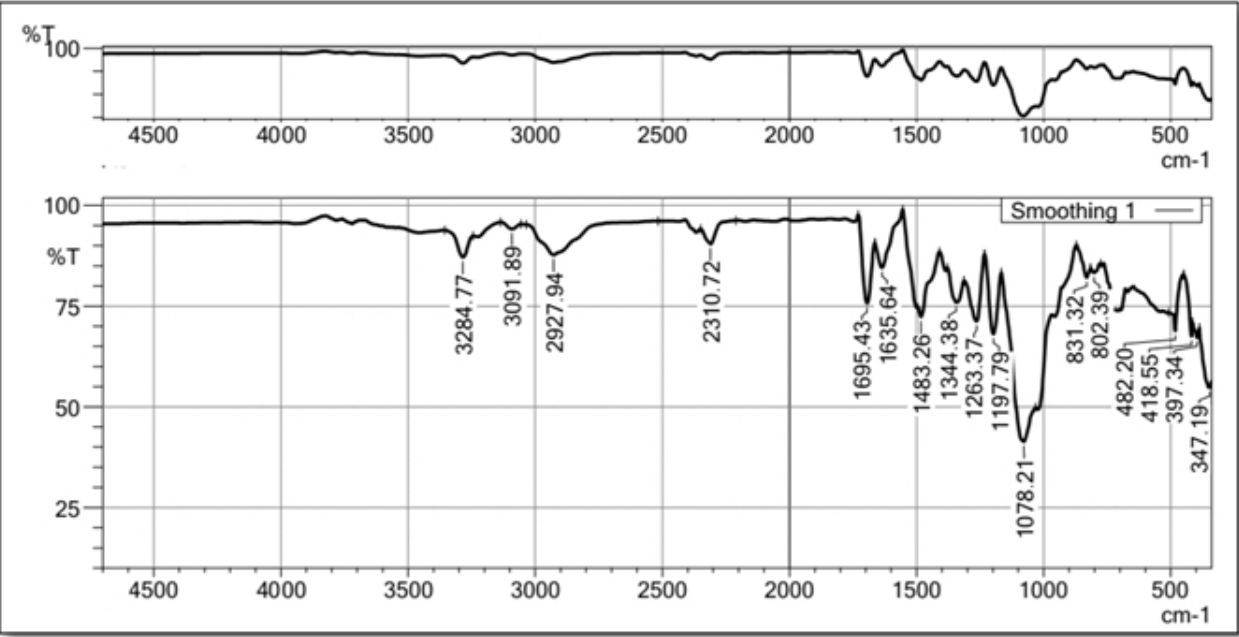

Fig. 2: IR spectrum of Cilnidipine and polymers (HPMC E15 and HPMC K4M)

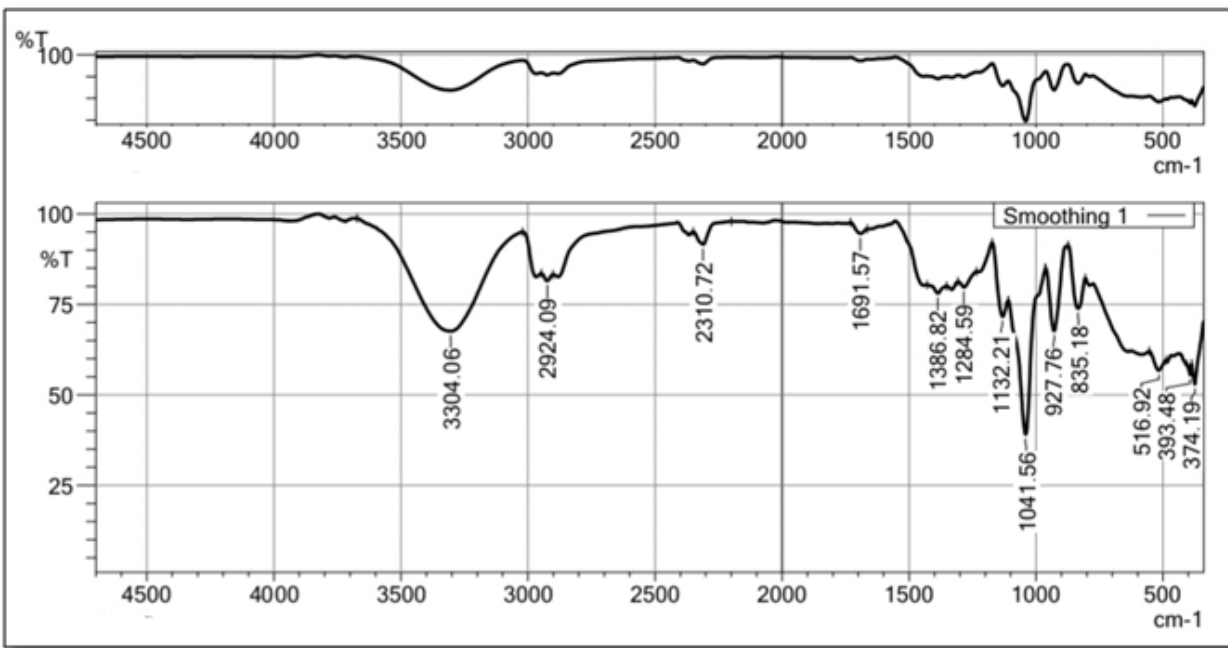

Fig. 3: IR spectrum of cilnidipine and plasticizer (Propylene glycol) 


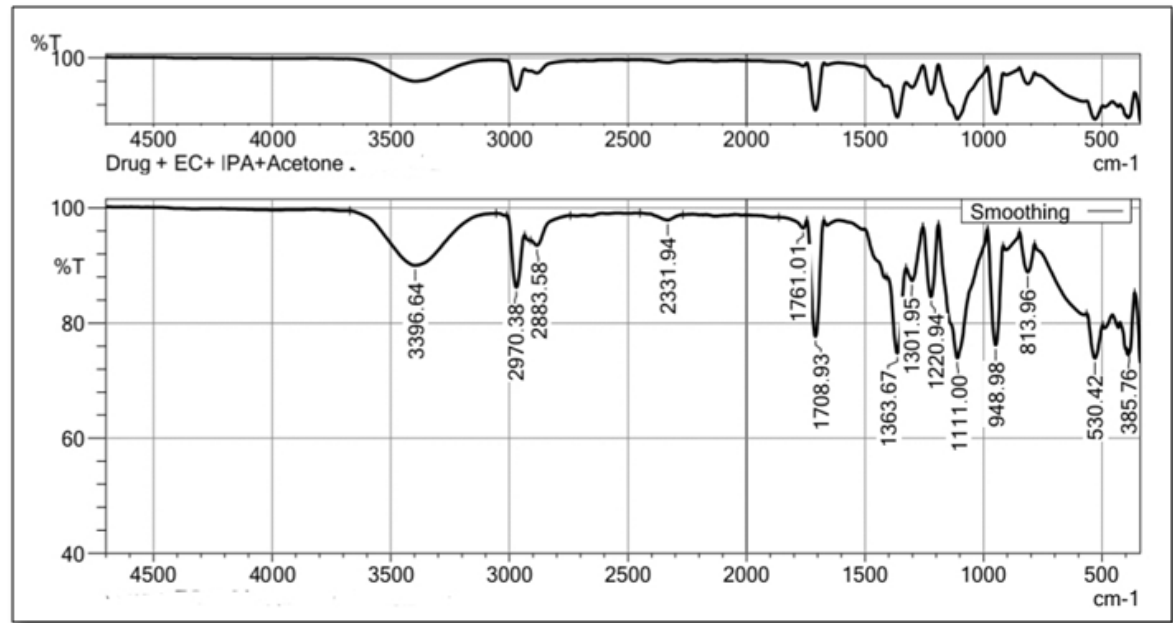

Fig. 4: IR spectrum of cilnidipine and backing layer (Ethyl cellulose, Acetone, Isopropyl alcohol)

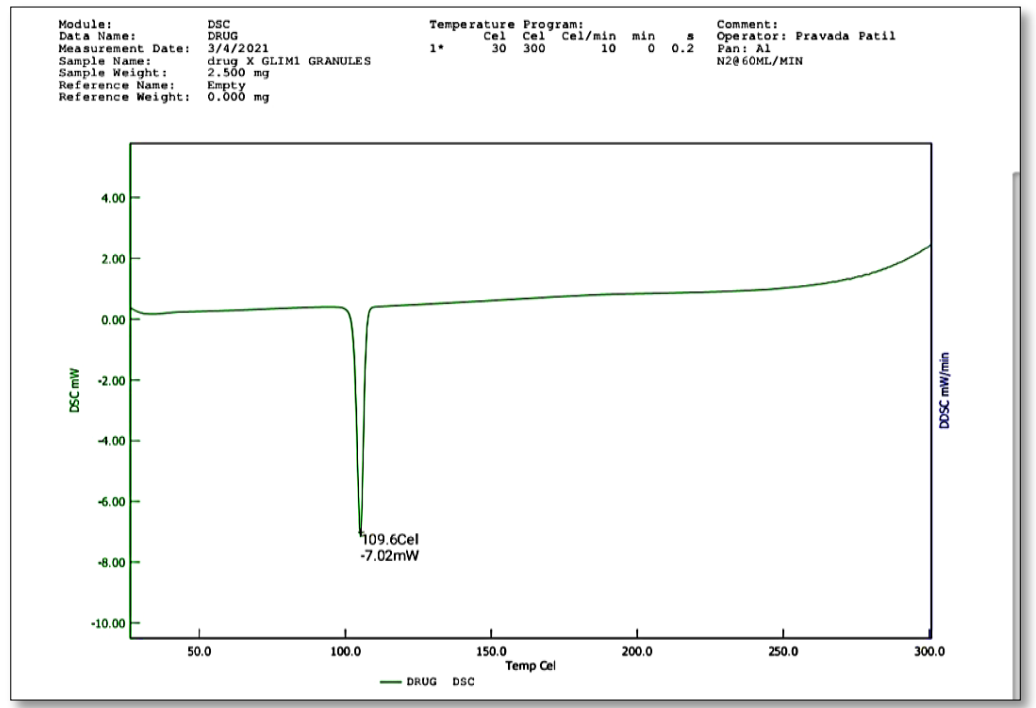

Fig. 5: DSC thermogram of cilnidipine

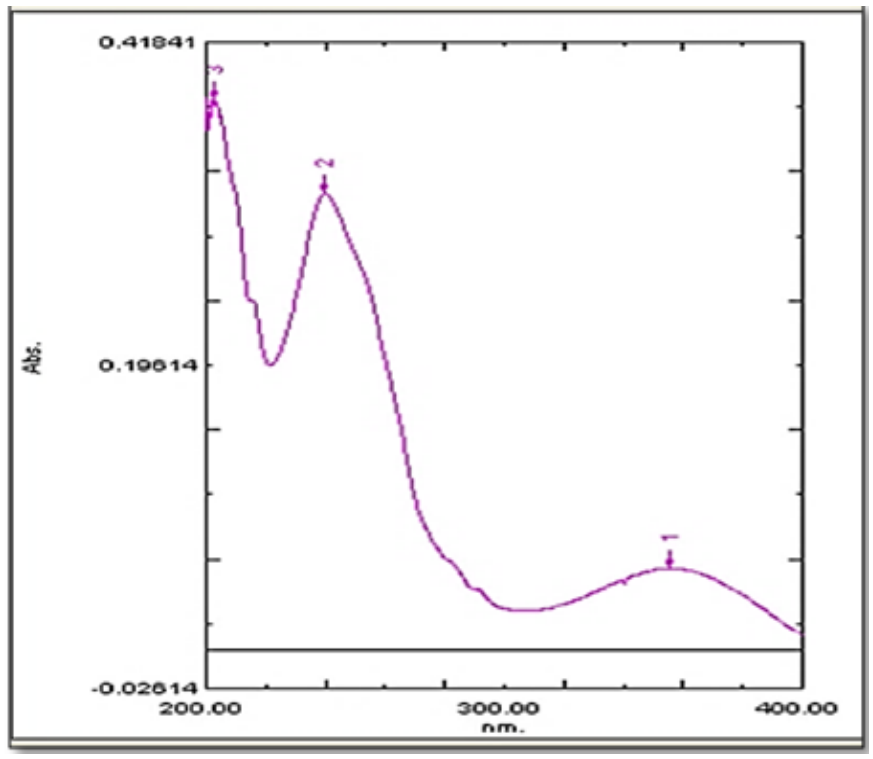

Fig. 6: UV spectrum of cilnidipine 
Table 2: Infrared spectral assignment for cilnidipine

\begin{tabular}{|c|c|c|c|c|c|c|}
\hline $\begin{array}{l}\text { S. } \\
\text { No. }\end{array}$ & Functional group & $\begin{array}{l}\text { Reported } \\
\text { frequency }\left(\mathrm{cm}^{-1}\right)\end{array}$ & $\begin{array}{l}\text { Frequency of } \\
\text { drug }\left(\mathrm{cm}^{-1}\right)\end{array}$ & $\begin{array}{l}\text { Frequency of drug } \\
\text { and polymer }\left(\mathrm{cm}^{-1}\right)\end{array}$ & $\begin{array}{l}\text { Frequency of drug } \\
\text { and plasticizer }\left(\mathrm{cm}^{-1}\right)\end{array}$ & $\begin{array}{l}\text { Frequency of drug and } \\
\text { backing layer }\left(\mathrm{cm}^{-1}\right)\end{array}$ \\
\hline 1. & $\begin{array}{l}\mathrm{C}-\mathrm{N} \text { Aromatic } 2^{\circ} \\
\text { amine }(\mathrm{S})\end{array}$ & $1020-1250$ & 1197.79 & 1132.21 & 1197.79 & 1111.00 \\
\hline 2. & $\mathrm{~N}-\mathrm{O}(\mathrm{S})$ & $1360-1550$ & 1344.38 & 1386.82 & 1344.38 & 1363.67 \\
\hline 3. & $\mathrm{C}=\mathrm{O}(\mathrm{S})$ & $1630-1980$ & 1693.50 & 1691.57 & 1695.43 & 1708.93 \\
\hline 4. & $-\mathrm{OCH}_{3}$ & $2815-2950$ & 2935.66 & 2924.09 & 2927.94 & 2883.58 \\
\hline 5. & $\mathrm{C}-\mathrm{O}(\mathrm{S})$ & $1200-1225$ & 1261.45 & 1284.59 & 1263.37 & 1220.94 \\
\hline 6. & $\begin{array}{l}\mathrm{N}-\mathrm{H} \text { Aromatic } 2^{\circ} \\
\text { amine }(\mathrm{S})\end{array}$ & $3250-3400$ & 3282.84 & 3304.06 & 3284.77 & 8396.64 \\
\hline
\end{tabular}

From the above results it could be inferred that the drug remained intact and no chemical interaction appeared to occur betwe en the drug and excipients therein.

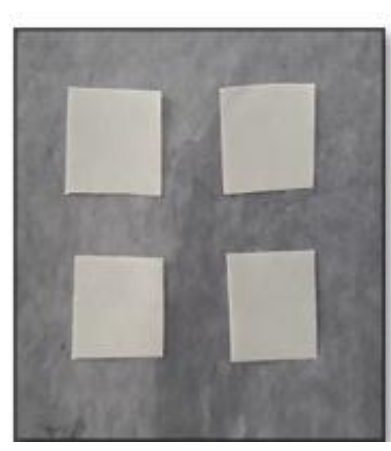

(a)

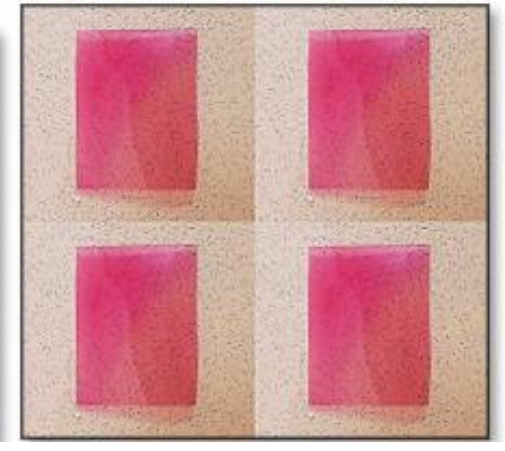

(b)

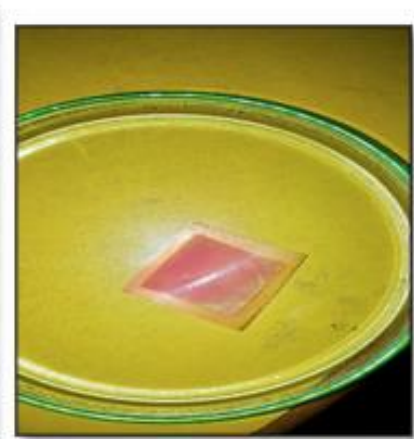

(c)

Fig. 7: (a) optimized formulation (F5) of Mucoadhesive buccal film. (b) Backing layer. (c) Buccal patch containing mucoadhesive buccal film with backing layer

\section{DSC thermogram of drug}

The DSC analysis of the drug was performed. The melting point of Cilnidipine was determined, exhibiting a sharp endothermic peak at $109.6^{\circ} \mathrm{C}$ (fig. 5) (Reported value: $108^{\circ}-110^{\circ} \mathrm{C}$ ) within the reported range, which confirms the melting point and thereby the purity of drugs [23].

\section{Determination of $\lambda$ max}

A concentration of $10 \mu \mathrm{g} / \mathrm{ml}$ was prepared from a standard Cilnidipine solution scanned by a UV-visible spectrometer in the range of 200-400 nm using 6.8 PBS as blank then the maximum wavelength ( $\lambda$ max) was determined (fig. 6).

\section{Preparation and physical characterization of cilnidipine mucoadhesive buccal film}

Preliminary feasibility trials were prepared with different polymers like HPMC (E3, E5, E15 and K4M) and plasticizer propylene glycol. Finally, from the trails made and results obtained, HPMC (E15, K4M) and plasticizer propylene glycol were selected with different levels for further formulation development [24].

\section{Evaluation of prepared mucoadhesive buccal films}

\section{Appearance}

The physical appearance and flexibility were noted visually, for all the films from F1 to F9 were creamish yellow in color, smooth, homogeneity and elegant in appearance [25].

\section{Weight variation}

The weight of mucoadhesive buccal film was determined using digital weighing balance and the average weight of all film (F1 to F9) was found to be in the range of $58-81 \mathrm{mg}$. From the result, it was observed that the weight of films increases with the increased in the polymer concentration ratio. The drug-loaded buccal film patches were found to be uniform [26].

\section{Thickness of films}

The average thickness of all the films ranges from $0.0754 \pm 0.002$ to $0.165 \pm 0.001 \mathrm{~mm}$. F1 shows the lowest thickness and F9 shows the highest thickness value. All the film shows a low standard deviation that may be due to good positioning during the solvent evaporation process. The measured thickness of F1-F9 films was approximately less than $1 \mathrm{~mm}$ which implies their usefulness for buccal application with least discomfort to the patients [27].

\section{Folding endurance}

The average folding endurance value of all the mucoadhesive buccal films ranges from $126 \pm 1$ to $215 \pm 3$. The values were optimum to reveal good buccal film properties. Formulation F1 shows the highest folding endurance value and F9 shows the lowest folding endurance value [28].

\section{Mucoadhesive strength}

The mucoadhesive strength values ranged from $4.5 \pm 0.5$ to $8.4 \pm 0.2$. Formulation F1 shows the lowest mucoadhesive strength value and F9 shows the highest mucoadhesive strength value. The present of hydrophilic group in polymer bind to mucin through hydrogen bond; leading to increase in mucoadhesive strength interaction. The Formulation F1 and F2 have lowest polymer concentration; thus, have lowest mucoadhesion. The formulation F9 shows highest mucoadhesive strength; as the attached buccal film can make the removal difficult from buccal cavity, which may cause discomfort to patient [29].

\section{Swelling index}

Swelling index of all formulations was evaluated. The swelling index values of the film ranges from $19.99 \pm 1.04$ to $35.23 \pm 3.43$. The formulation F1 showed the lowest swelling index and formulation F9 showed the highest swelling index. Swelling increases with the increase in HPMC concentration due to the presence of more hydroxyl group [29]. 


\section{Surface-pH}

The surface-pH was noted by $\mathrm{pH}$ meter near the surface of mucoadhesive buccal film and allowed for equilibration and the surface-pH of all film was found to be in the range of 6.67 to $6.73 \mathrm{pH}$ $(\mathrm{n}=3)$. All the formulation batches show $\mathrm{pH}$ in neutral range, which indicates for the absences of buccal irritation [30].

\section{Drug content}

The percent of drug content for all the formulations F1 to F9 was obtained in the range of $92.13 \% \pm 0.94 \%$ to $97.92 \% \pm 0.35 \%$. The results indicate that the drug is distributed uniformly in all film formulations and will deliver the dose of drug accurately [30].

\section{Percent moisture absorption}

The percentage moisture uptake is referred to the function of the excipient to absorb the moisture in the form of water vapors. The percent moisture absorption of all formulations from F1 to F9 was estimated. The average \% moisture absorption was found in the range of $1.59 \pm 0.29 \%$ to $3.28 \pm 0.15 \%$. All formulation shows moisture absorption within limits that is evidence for the physical stability of the film in humid conditions [31].

\section{Percent moisture loss}

The percent moisture loss of all formulations from F1 to F9 was estimated. The average \% moisture loss was found in the range of $1.03 \pm 0.05 \%$ to $2.32 \pm 0.22 \%$. All formulation shows moisture loss within limits that is evidence for the stability of the film against microbial growth [31]

\section{Tensile strength}

Tensile strength of prepared buccal film varies from $3.09 \pm 0.12$ to $21.25 \pm 0.42 \mathrm{~N} / \mathrm{mm}^{2}$ revealing that the films had good mechanical strength and flexibility. Tensile strength of buccal film increases with the increase in the polymeric concentration. Formulation F1 showed the lowest tensile strength, whereas formulation F9 showed the highest tensile strength [32].

\section{In vitro residence time}

The in vitro-residence time of all formulations from F1 to F9 was evaluated of film ranges from $1.85 \pm 0.03$ to $4.70 \pm 0.31$. The in vitro residence time of all the films were found to be optimum and therefore, films exhibited good swelling and drug release properties [33].

Table 3: Evaluation of mucoadhesive buccal film of cilnidipine

\begin{tabular}{llllc}
\hline $\begin{array}{l}\text { Formulation } \\
\text { code }\end{array}$ & $\begin{array}{l}\text { Weight } \\
\text { variation (mg) }\end{array}$ & Thickness (mm) & $\begin{array}{l}\text { Folding endurance } \\
\text { (folds) }\end{array}$ & $\begin{array}{l}\text { Mucoadhesive } \\
\text { strength }\end{array}$ \\
\hline F1 & $58.73 \pm 0.63$ & $0.0754 \pm 0.002$ & $215.66 \pm 2.08$ & $4.5 \pm 0.5$ \\
F2 & $64.61 \pm 0.54$ & $0.119 \pm 0.001$ & $190.66 \pm 2.08$ & $4.30 \pm 0.09$ \\
F3 & $73.66 \pm 0.57$ & $0.135 \pm 0.001$ & $181.66 \pm 1.52$ & $5.33 \pm 0.57$ \\
F4 & $66.2 \pm 0.88$ & $0.125 \pm 0.001$ & $163.66 \pm 2.51$ & $4.8 \pm 0.26$ \\
F5 & $69.87 \pm 0.45$ & $0.126 \pm 0.005$ & $177.66 \pm 3.05$ & $5.66 \pm 0.15$ \\
F6 & $78.61 \pm 0.60$ & $0.149 \pm 0.001$ & $151.66 \pm 1.52$ & $6.2 \pm 0.2$ \\
F7 & $70.56 \pm 0.51$ & $0.134 \pm 0.001$ & $183.66 \pm 2.08$ & $6.5 \pm 0.1$ \\
F8 & $77.33 \pm 0.57$ & $0.154 \pm 0.001$ & $156.66 \pm 2.08$ & 6.01 \\
F9 & $80.63 \pm 0.55$ & $0.165 \pm 0.001$ & $126.33 \pm 0.57$ & $9.02 \pm 0.1$ \\
\hline
\end{tabular}

All data are given in mean $\pm \mathrm{SD}$

Table 4: Evaluation of mucoadhesive buccal film of cilnidipine

\begin{tabular}{lllll}
\hline $\begin{array}{l}\text { Formulation } \\
\text { code }\end{array}$ & $\begin{array}{l}\text { Percent moisture } \\
\text { absorption (\%) }\end{array}$ & $\begin{array}{l}\text { Percent moisture } \\
\text { loss (\%) }\end{array}$ & $\begin{array}{l}\text { Tensile strength } \\
\mathbf{N} / \mathbf{m m}^{2}\end{array}$ & $\begin{array}{l}\text { Swelling } \\
\text { index }\end{array}$ \\
\hline F1 & $2.74 \pm 0.11$ & $2.32 \pm 0.22$ & $3.09 \pm 0.12$ & $19.99 \pm 1.04$ \\
F2 & $3.22 \pm 0.04$ & $2.04 \pm 0.02$ & $5.06 \pm 0.17$ & $25.41 \pm 0.79$ \\
F3 & $3.28 \pm 0.15$ & $2.28 \pm 0.12$ & $10.08 \pm 0.40$ & $30.18 \pm 0.33$ \\
F4 & $2.18 \pm 0.31$ & $1.44 \pm 0.02$ & $7.39 \pm 0.41$ & $32.63 \pm 0.38$ \\
F5 & $1.59 \pm 0.29$ & $1.55 \pm 0.03$ & $14.09 \pm 0.71$ & $22.18 \pm 0.97$ \\
F6 & $1.69 \pm 0.42$ & $1.53 \pm 0.01$ & $16.22 \pm 0.39$ & $2.06 \pm 0.03$ \\
F7 & $1.76 \pm 0.61$ & $1.33 \pm 0.08$ & $17.06 \pm 0.61$ & $3.07 \pm 0.03$ \\
F8 & $2.00 \pm 0.40$ & $1.46 \pm 0.01$ & $19.09 \pm 0.44$ & $3.92 \pm 0.06$ \\
F9 & $1.72 \pm 0.37$ & $1.03 \pm 0.05$ & $21.25 \pm 0.42$ & 26.05 \\
\hline
\end{tabular}

All data are given in mean \pm SD

Table 5: In vitro drug release of cilnidipine mucoadhesive buccal film

\begin{tabular}{|c|c|c|c|c|c|c|c|c|c|}
\hline \multirow[t]{2}{*}{ Time duration } & \multicolumn{9}{|c|}{ Cumulative \% drug release } \\
\hline & F1 & F2 & F3 & F4 & F5 & F6 & F7 & F8 & F9 \\
\hline $15 \mathrm{~min}$ & $1.89 \pm 0.02$ & $3.08 \pm 0.05$ & $1.33 \pm 0.02$ & $3.40 \pm 0.02$ & $4.70 \pm 0.02$ & $2.37 \pm 0.05$ & $2.38 \pm 0.08$ & $2.38 \pm 0.04$ & $2.98 \pm 0.02$ \\
\hline $30 \mathrm{~min}$ & $4.62 \pm 0.08$ & $6.73 \pm 0.05$ & $4.82 \pm 0.04$ & $7.69 \pm 0.06$ & $9.49 \pm 0$ & $7.015 \pm 0.06$ & $4.87 \pm 0.09$ & $6.10 \pm 0.14$ & $7.16 \pm 0.81$ \\
\hline $45 \min$ & $10.45 \pm 0.07$ & $11.94 \pm 0.08$ & $10.91 \pm 0.03$ & $13.29 \pm 0.08$ & $15.47 \pm 0.02$ & $12.42 \pm 0.06$ & $10.32 \pm 0.10$ & $11.68 \pm 0.12$ & $12.60 \pm 0.78$ \\
\hline $1 \mathrm{~h}$ & $18.54 \pm 0.06$ & $20.35 \pm 0.02$ & $19.16 \pm 0.05$ & $21.62 \pm 0.13$ & $23.74 \pm 0.02$ & $20.74 \pm 0.05$ & $18.32 \pm 0.11$ & $19.68 \pm 0.09$ & $20.17 \pm 0.74$ \\
\hline $2 \mathrm{~h}$ & $27.59 \pm 0.03$ & $29.24 \pm 0.03$ & $28.03 \pm 0.15$ & $30.43 \pm 0.15$ & $33.00 \pm 0.17$ & $29.56 \pm 0.11$ & $26.97 \pm 0.17$ & $34.14 \pm 9.92$ & $28.95 \pm 0.66$ \\
\hline $4 \mathrm{~h}$ & $38.36 \pm 0.11$ & $38.62 \pm 0.09$ & $38.71 \pm 0.11$ & $39.64 \pm 0.13$ & $43.95 \pm 0.11$ & $39.25 \pm 0.22$ & $37.77 \pm 0.16$ & $39.17 \pm 0.05$ & $39.40 \pm 0.59$ \\
\hline $6 \mathrm{~h}$ & $49.89 \pm 0.04$ & $49.50 \pm 0.05$ & $49.53 \pm 0.13$ & $50.54 \pm 0.13$ & $55.32 \pm 0.06$ & $50.61 \pm 0.25$ & $48.53 \pm 0.13$ & $50.08 \pm 0.09$ & $50.21 \pm 0.59$ \\
\hline $8 \mathrm{~h}$ & $63.69 \pm 0.03$ & $63.16 \pm 0.04$ & $63.09 \pm 0.13$ & $63.77 \pm 0.19$ & $67.97 \pm 0.10$ & $63.51 \pm 0.23$ & $61.96 \pm 0.11$ & $62.89 \pm 0.13$ & $61.75 \pm 0.63$ \\
\hline $12 \mathrm{~h}$ & $78.04 \pm 0.02$ & $76.98 \pm 0.12$ & $77.18 \pm 0.17$ & $77.23 \pm 0.15$ & $81.21 \pm 0.06$ & $77.06 \pm 0.21$ & $75.72 \pm 0.16$ & $76.06 \pm 0.20$ & $75.18 \pm 0.60$ \\
\hline $24 \mathrm{~h}$ & $92.73 \pm 0.08$ & $91.45 \pm 0.12$ & $91.32 \pm 0.18$ & $91.40 \pm 0.12$ & $95.18 \pm 0.03$ & $91.04 \pm 0.22$ & $90.33 \pm 0.19$ & $90.16 \pm 0.23$ & $89.31 \pm 0.57$ \\
\hline
\end{tabular}

All data are given in mean $\pm \mathrm{SD}$ 


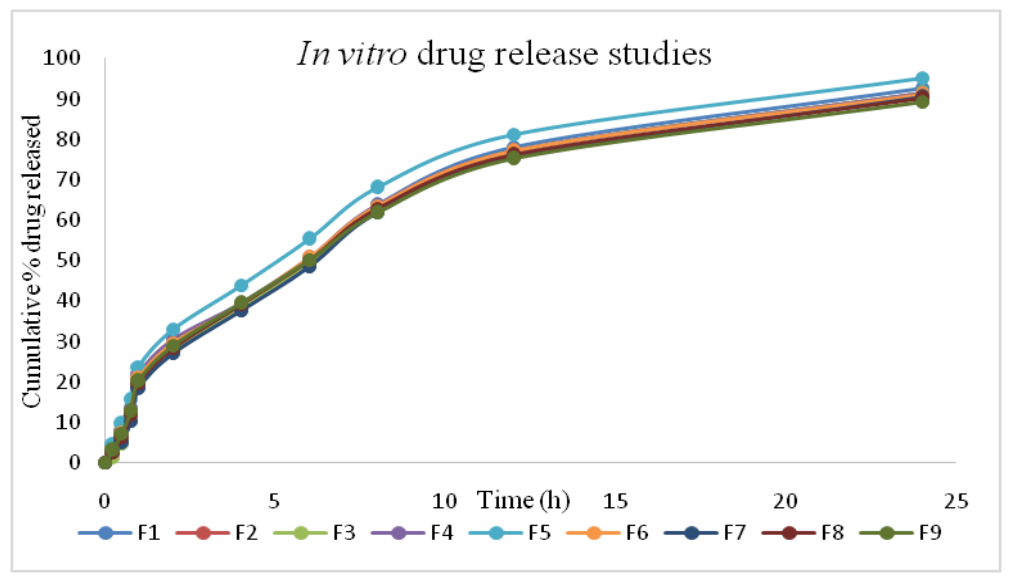

Fig. 8: In vitro drug release profile of cilnidipine mucoadhesive buccal film

\section{In vitro drug release}

In vitro dissolution of Cilnidipine mucoadhesive buccal film investigation was carried out in $\mathrm{pH}$ 6.8 PBS. Drug release from F1 to F9 was found to be ranges of $89.31 \pm 0.57 \%$ to $95.18 \pm 0.03 \%$. It was observed that the drug release slower with increasing polymer concentration. The formulation F5 was selected as an optimized formulation based on these in vitro release studies which showed satisfactory drug release rate $95.18 \pm 0.03 \%$ in $24 \mathrm{~h}$. The selected optimized formulation F5 was used further for the evaluation of exvivo permeation studies through goat buccal mucosa [34]

\section{In vitro diffusion studies}

In vitro diffusion of all formulations ranges from $76.63 \pm 0.30 \%$ to $82.64 \pm 0.30 \%$. In the case of F series formulations, F1, initially, the drug release was rapid, more than $60 \%$ in $2 \mathrm{~h}$ and followed by slow release and showed about $79.73 \pm 0.17 \%$ in $24 \mathrm{~h}$ respectively. The formulation
F4 and F5 had shown $57.28 \pm 0.173 \%$ and $62.59 \pm 0.173 \%$ in $4 \mathrm{~h}$. There appeared no remarkable difference in the final percentage of drug diffusion, which might be due to fact that in all formulations, the drug dissolved completely in the medium. It is clear from the plots the drug diffusion was governed by the polymer content.

No lag time was observed as the buccal film was directly exposed to the medium. An increase in the polymer content was associated with decrease in release rate of the drug. Since increasing the amount of polymer in the buccal film forms a water-swollen gel-like state that could considerably reduce the penetration of medium into the buccal film then the drug release was retarded.

The formulation F5 was selected as an optimized formulation based on the in vitro diffusion studies which showed a satisfactory diffusion rate $82.64 \pm 0.30 \%$ in $24 \mathrm{~h}$. The selected optimized formulation F5 was used further for the evaluation of ex-vivo permeation studies through goat buccal mucosa [35].

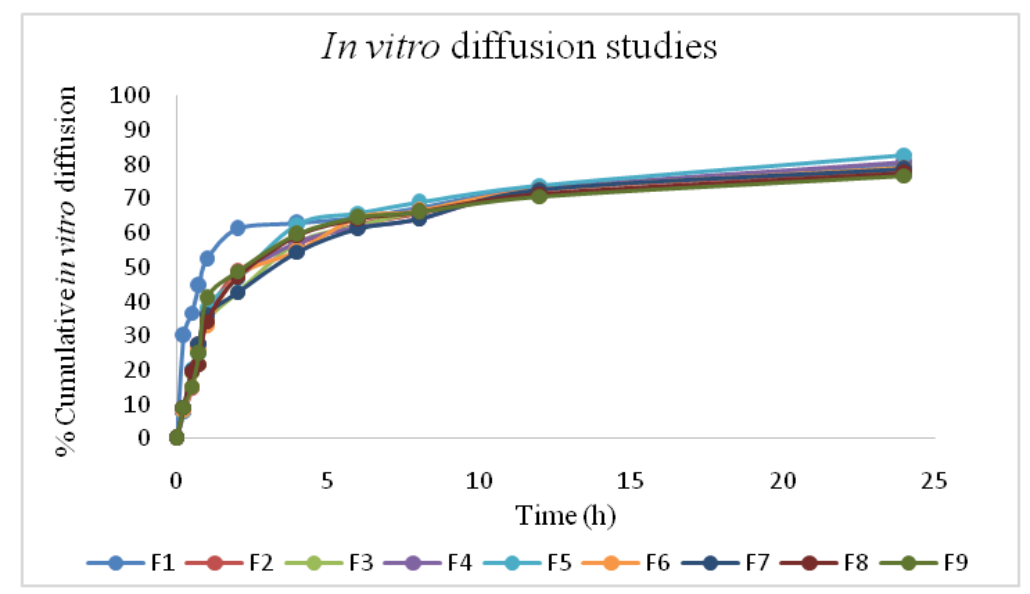

Fig. 9: In vitro diffusion profile of cilnidipine mucoadhesive buccal film

\section{Ex-vivo permeation studies}

The formulation F5 was selected as optimum for the ex-vivo permeation studies due to adequate in vitro drug release, in vitro diffusion and mucoadhesive studies. The result of drug permeation from the mucoadhesive buccal film containing backing layer acting as a patch providing unidirectional drug release of Cilnidipine through the goat buccal mucosa reveals that drug was released from formulation and permeated through the goat buccal membrane and hence can feasibly be permeated through the human buccal membrane. The result indicated that the drug permeation was slow and steady and $76.34 \pm 0.17 \%$ of Cilnidipine permeate through the buccal membrane from the optimized formulation in $24 \mathrm{~h}$ [36]. The cumulative percentage amount of Cilnidipine that had penetrated through the buccal epithelium from the buccal film was shown in the fig. 10.

\section{Stability studies}

Based on the above result, stability studies were conducted only for optimized formulation F5. Form the stability studies, it was known that optimized formulation F5 had stability in human saliva; there was no change in the color and integrity of the buccal film. The optimized formulation F5 was selected for short term stability studies at temperature $25 \pm 2{ }^{\circ} \mathrm{C}$ and $60 \pm 5 \% \mathrm{RH}$ and accelerated stability studies were carried out at $40 \pm 2{ }^{\circ} \mathrm{C}$ and $75 \pm 5 \%$ RH for the 
period of 3months. The buccal film patches were analyzed for folding endurance, tensile strength, drug content and in vitro drug release. There was a minor decrease in all the parameters [37]. Hence the formulation F5 was indicated stable.

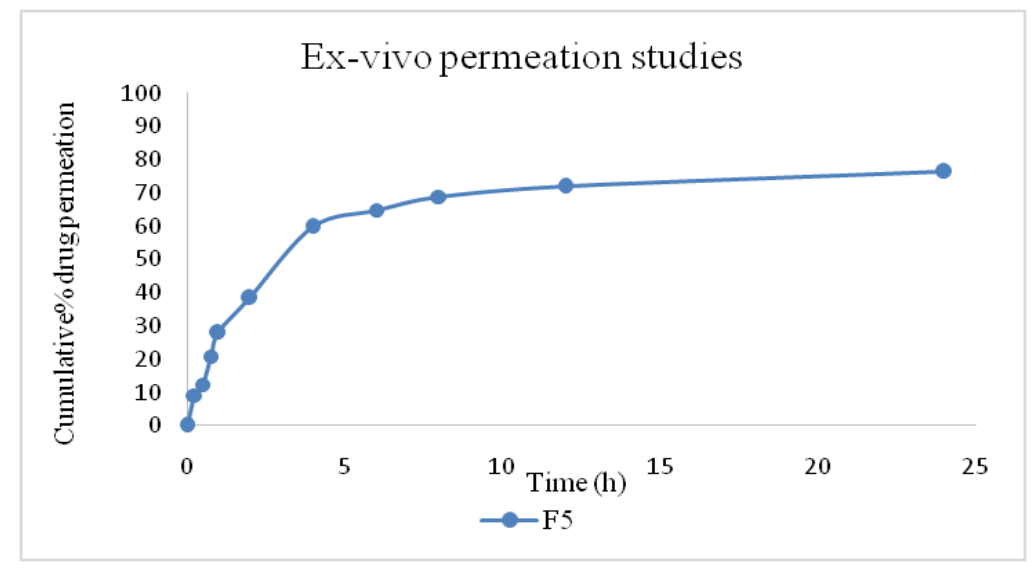

Fig. 10: Ex-vivo permeation of cilnidipine mucoadhesive buccal film (buccal patch)

Table 6: Short term and accelerated stability studies of optimized batch F5

\begin{tabular}{|c|c|c|c|c|c|c|c|c|}
\hline \multirow{2}{*}{$\begin{array}{l}\text { Time } \\
\text { (d) }\end{array}$} & \multicolumn{4}{|c|}{$25^{\circ} \pm 2{ }^{\circ} \mathrm{C} / 60 \% \mathrm{RH} \pm 5 \% \mathrm{RH}$} & \multicolumn{4}{|c|}{$40^{\circ} \pm 2{ }^{\circ} \mathrm{C} / 75 \% \mathrm{RH} \pm 5 \% \mathrm{RH}$} \\
\hline & $\begin{array}{l}\text { Folding } \\
\text { endurance }\end{array}$ & $\begin{array}{l}\text { Tensile } \\
\text { strength }\end{array}$ & $\begin{array}{l}\text { Drug } \\
\text { content }\end{array}$ & $\begin{array}{l}\text { In vitro drug } \\
\text { release }\end{array}$ & $\begin{array}{l}\text { Folding } \\
\text { endurance }\end{array}$ & $\begin{array}{l}\text { Tensile } \\
\text { strength }\end{array}$ & $\begin{array}{l}\text { Drug } \\
\text { content }\end{array}$ & $\begin{array}{l}\text { In vitro drug } \\
\text { release }\end{array}$ \\
\hline 0 & $177.66 \pm 3.05$ & $14.09 \pm 0.71$ & $97.92 \pm 0.35$ & $95.18 \pm 0.03$ & $177.66 \pm 3.05$ & $14.09 \pm 0.71$ & $97.92 \pm 0.35$ & $95.18 \pm 0.03$ \\
\hline 30 & $174.33 \pm 1.52$ & $13.97 \pm 0.52$ & $97.51 \pm 0.62$ & $95.13 \pm 0.05$ & $169.66 \pm 1.52$ & $13.88 \pm 0.65$ & $97.30 \pm 0.94$ & $95.11 \pm 0.07$ \\
\hline 60 & $169 \pm 1$ & $13.61 \pm 0.24$ & $97.30 \pm 0.35$ & $95.07 \pm 0.03$ & $166.33 \pm 0.57$ & $13.56 \pm 0.70$ & $97.10 \pm 0.94$ & $95.01 \pm 0.05$ \\
\hline 90 & $166.33 \pm 1.52$ & $13.42 \pm 0.44$ & $97.10 \pm 0.35$ & $95.02 \pm 0.07$ & $163.66 \pm 0.57$ & $13.34 \pm 0.70$ & $96.89 \pm 0.62$ & $94.96 \pm 0.09$ \\
\hline
\end{tabular}

All data are given in mean \pm SD

\section{CONCLUSION}

Buccal delivery is an appealing alternative route for the administration of drugs that has low bioavailability because of extensive first-pass metabolism. The following conclusion could be drawn from the various experiments. FTIR studies concluded that there was no drug and excipients interaction. The mucoadhesive buccal film containing backing layer, which acts like a patch providing unidirectional drug release of Cilnidipine, could be prepared by the solvent casting technique with mucoadhesive polymers like HPMC E15 and HPMC $\mathrm{K} 4 \mathrm{M}$. The prepared films were smooth, flexible and elegant in appearance with uniform in weight, thickness, drug content uniformity and showing good folding endurance. The physicochemical properties of all formulations were shown to be within limits. The surface $\mathrm{pH}$ of all formulations was in an acceptable salivary $\mathrm{pH}$ (5.8 to 7.4). Among that formulation, F5 shows better drug release, mucoadhesive properties, drug content, tensile strength and accelerated stability conditions were found to be stable at specified by ICH. So that F5 batch considered as optimized formulation. Ex-vivo permeation studies for optimized batch were conducted and shown satisfactory drug permeation. Cilnidipine could permeate through goat buccal membrane as evidenced from the ex-vivo permeation studies. Hence, present study concludes that the Cilnidipine could be delivered through the buccal route.

\section{ACKNOWLEDGMENT}

The authors are thankful to Pure Chem Pvt. Ltd., for providing Cilnidipine drug and Colorcon Pvt. Ltd., for providing film-forming polymers as gift samples for this work. I express my sincere gratitude towards Mr. (Dr.) Mohd Wais, Associate Professor, and $\mathrm{H}$. K. College of Pharmacy who has been abundantly helpful in numerous ways for this research work. The authors also thank H. K. College of Pharmacy, Mumbai, Maharashtra, India, for providing the required facilities to carry out this research work.

\section{FUNDING}

No funding was provided for this study.

\section{AUTHORS CONTRIBUTIONS}

The literature search, manuscript framing, preparation, design and drafting the article is done by Shifa Haju. Reviewing it critically for important intellectual content and final editing of the manuscript is done by Dr. Sheela Yadav.

\section{CONFLICT OF INTERESTS}

The authors have declared no conflicts of interest.

\section{REFERENCES}

1. Chien YW. Novel drug delivery systems. $2^{\text {nd }}$ ed. Marcel Dekker, New York, Revised and expanded; 1982. p. 197-228.

2. Indira MY, Kumari SK. Mucoadhesive buccal films of glibenclamide: development and evaluation. Int J Pham Investigation 2011;1:42-7.

3. Arun JL, Rani S, Kumar MP. Buccal drug delivery system: history and recent developments. Asian J Pharm Clin Res 2016;9:36-42.

4. Madhavi RB, Murthy VSN, Rani PA, Gattu DK. Buccal film drug delivery system-an innovative and emerging technology. J Mol Pharm Org Process Res 2013;1:100-107.

5. Smalt A, Semalty M, Nautiyal U. Formulation and evaluation of mucoadhesive buccal films of enalapril maleate. Indian J Pharm Sci 2010;72:571-5.

6. Sudhakar Y, Kuotsu K, Bandyopadhyay AK. Buccal bioadhesive drug delivery-a promising option for orally less efficient drugs. J Controlled Release 2006;114:15-40.

7. Haju S, Yadav S, Baig R, Sawant G. Buccal film: a novel approach for oral mucosal drug delivery system. Asian J Pharm Clin Res 2021;14:27-35.

8. Bhati R, Nagarajan RK. A detailed review on oral mucosal drug delivery system. Int J Pharm Sci Res 2011;3:659-81.

9. Bhalerao A, Choudhari P. Formulation of solid lipid nanoparticle of cilnidipine for treatment of hypertension. J Drug Delivery Ther 2019;9:212-21.

10. Yelave A, Bhagwat G. Mucoadhesive buccal films: a novel approach for the delivery of anti-hypertensive drugs. Asian J Pharm Clin Res 2021;14:12-21. 
11. Patel Z, Bhura R, Shah S. Formulation optimization and evaluation of mouth dissolving film of ramosteron hydrochloride. Int J Curr Pharm Res 2020;12:99-106.

12. Jagtap VD. Buccal film-a review on novel drug delivery system. Int J Res Rev 2020;7:17-28.

13. Al-Dhubiab BE, Nair AB, Kumria R, Attimarad M, Sree $H$. Development and evaluation of buccal films impregnated with selegiline-loaded nanosphere. Drug Delivery 2016;23:2154-62.

14. Nair AB, Kumari R, Harsha S, Attimarad M, Al-Dhubiab BE, Alhaider IA. In vitro techniques to evaluate buccal films. J Controlled Release 2013;166:10-21.

15. Lodhi M, Dubey A, Narayan R, Prabhu P, Sneh P. Formulation and evaluation of buccal film of invbradine hydrochloride for the treatment of stable angina pectoris. Int J Pharm Ivestig 2013;3:47-53.

16. Alagusundaram M, Chetty CM, Dhachinamoorthi D. Development and evaluation of novel-trans-buccoadhesive films of famotidine. J Adv Pharm Technol Res 2011;2:17-23.

17. Surini S, Gotalia F, Putri KSS. Formulation of mucoadhesive buccal films using pregelatinized cassava starch phthalate as a film-forming polymer. Int J Appl Pharm 2018;10:225-9.

18. Raghavendra Rao NG, Suryakar VB. Formulation and evaluation of montelukast sodium mucoadhesive buccal patches for chronic asthma attacks. Int J Pharm Bio Sci 2010;1:1-14

19. Salehi S, Boddohi S. New formulation and approach for mucoadhesive buccal film of rizatriptan benzoate. Prog Biomater 2017;6:175-87.

20. Morales JO, McConville JT. Manufacture and characterization of mucoadhesive buccal films. Eur J Pharm Biopharm 2011;77:187-99.

21. Suvarna DS, Koland M, Prabhu A, Sindhoor SM. Mucoadhesive polymeric films of acyclovir proniosomes for buccal administration. Int J Appl Pharm 2021;13:135-43.

22. Kumar BV, Kumar AA, Sudheer B, Kumar SK, Rao SV, Kirtinidhi $\mathrm{K}$, et al. Formulation design, in vitro evaluation and stability studies on mucoadhesive buccal films of anti-anginal calcium channel blocker. J Appl Pharm Sci 2011;1:136-42.

23. Prajapati ST, Maheshwari PD, Patel CN. Formulation and evaluation of orodispersible tablets of cilnidipine by spray drying techniques. World J Pharm Pharm Sci 2015;5:1526-39.

24. Hanif M, Zaman M, Chaurasiya V. Polymers used in buccal film: a review. Design Monomers Polymers 2015;18:105-11.
25. Mishra SK, Guard N, Singh R. Development and evaluation of mucoadhesive buccal patch of flurbiprofen. Pharma Technol 2011;68 Suppl 6:955-64.

26. Lohani A, Prasad N, Rajeshwar KKA. Formulation and characterization of mucoadhesive buccal films of ranitidine hydrochloride. Int J Pharm Sci 2011;2:2547-462.

27. Nair AB, Al-Dhubiab BE, Shah J, Jacob S, Saraiya V, Attimardd M, et al. Mucoadhesive buccal film of amlotriptan improved therapeutic delivery in rabbit model. Saudi Pharm J 2020;28:201-9.

28. Patel VM, Prajapati BG, Patel MM. Design and characterization of chitosan-containing mucoadhesive buccal patches of propranolol hydrochloride. Acta Pharm 2007;57:61-72.

29. Peh KK, Wong CF. Polymeric films as a vehicle for buccal delivery: swelling, mechanical and bioadhesive properties. Int Pharm Pharm Sci 1999;2:53-61.

30. Malpure DR, Deore SL. Development and characterization of buccal film of candesartan. Pharm Methods 2016;7:75-88.

31. Nappinnai M, Chandanbala R, Balajirajan R. Formulation and evaluation of nitrendipine buccal films. Indian J Pharm Sci 2008;70:631-5.

32. Augusthy AR, Vipin KV, Chandran S, Thushara MV, Muhammed STK. Formulation and evaluation of mucoadhesive buccal film of lisnopril. Res Rev J Pharm Nanotechnol 2014;2:45-51.

33. Mane PP, Bushetti SS, Keshavshetti GG. Development and in vitro evaluation of mucoadhesive buccal film of nebivolol. Indian J Pharm Sci 2014;76:166-9.

34. Nafee NA, Ismail FA, Boraie NA, Mortada LM. Mucoadhesive buccal patches of miconazole nitrate: in vitro/in vivo performance and effect of ageing. Int J Pharm 2003;264 Suppl 1-2:1-14.

35. El Sharawy AM, Shur MH, Elshafeey AH. Formulation and optimization of duloxetine hydrochloride buccal films: in vitro and in vivo evaluation. Drug Delivery 2017;24:1762-9.

36. Sharma D, Sharma A, Garg R. Design, development and in vitro/ex-vivo evaluation of mucoadhesive buccal film of benzydamine hydrochloride for the effective treatment of aphthous stomatitis. Recent Pat Drug Delivery Formul 2018;12 Suppl 4:277-94

37. Gorle A, Patil P, Bhaskar R, Ola M. Development and evaluation of buccal film containing antihypertensive agent. Pharm Innova J 2015;4:53-60 